ARTICLE

\title{
Directional ionic transport across the oxide interface enables low-temperature epitaxy of rutile $\mathrm{TiO}_{2}$
}

Yunkyu Park', Hyeji Sim (1) 1, Minguk Jo', Gi-Yeop Kim', Daseob Yoon', Hyeon Han (10 1,2, Younghak Kim³, Kyung Song ${ }^{4}$, Donghwa Lee (i) ${ }^{1}$, Si-Young Choi (i) ${ }^{1} \&$ Junwoo Son (i) ${ }^{1 凶}$

Heterogeneous interfaces exhibit the unique phenomena by the redistribution of charged species to equilibrate the chemical potentials. Despite recent studies on the electronic charge accumulation across chemically inert interfaces, the systematic research to investigate massive reconfiguration of charged ions has been limited in heterostructures with chemically reacting interfaces so far. Here, we demonstrate that a chemical potential mismatch controls oxygen ionic transport across $\mathrm{TiO}_{2} / \mathrm{VO}_{2}$ interfaces, and that this directional transport unprecedentedly stabilizes high-quality rutile $\mathrm{TiO}_{2}$ epitaxial films at the lowest temperature $\left(\leq 150^{\circ} \mathrm{C}\right.$ ) ever reported, at which rutile phase is difficult to be crystallized. Comprehensive characterizations reveal that this unconventional low-temperature epitaxy of rutile $\mathrm{TiO}_{2}$ phase is achieved by lowering the activation barrier by increasing the "effective" oxygen pressure through a facile ionic pathway from $\mathrm{VO}_{2-\delta}$ sacrificial templates. This discovery shows a robust control of defect-induced properties at oxide interfaces by the mismatch of thermodynamic driving force, and also suggests a strategy to overcome a kinetic barrier to phase stabilization at exceptionally low temperature.

\footnotetext{
${ }^{1}$ Department of Materials Science and Engineering (MSE), Pohang University of Science and Technology (POSTECH), Pohang 37673, Republic of Korea. ${ }^{2}$ Max Planck Institute of Microstructure Physics, Weinberg 2, Halle (Saale) 06120, Germany. ${ }^{3}$ Pohang Accelerator Laboratory, Pohang 37673, Republic of Korea. ${ }^{4}$ Materials Modeling and Characterization Department, Korea Institute of Materials Science (KIMS), Changwon, Republic of Korea.

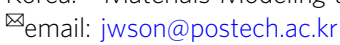


nterfaces formed by two dissimilar materials can break the translational symmetry and thereby provide an opportunity to develop functionality that is unachievable in bulk materials ${ }^{1-5}$. When two materials $(I, I I)$ that have different work functions (i.e., $\left.\mu_{e}^{I}<\mu_{e}^{I I}\right)$ are brought together at a semiconductor heterojunction, charge carriers near the interface diffuse across the junction (Fig. 1a);1,2 as a consequence, a conducting channel with high carrier density and high electron mobilities (e.g., two-dimensional electron gas) could be created at the interfaces between normallyinsulating materials ${ }^{2,3}$. If an external bias is applied to adjust this built-in potential, the amount of transferred charge flow can be controlled by changing the electrochemical potential across chemically-inert interfaces ${ }^{2,6}$, which is the basic principle of heterojunction field effect transistors (HFETs) ${ }^{7}$.

As an analogy to the reversible control of electric charge transfer at an interface with discontinuity, (electro-)chemical potential mismatch for oxygen $\left(\Delta \mu_{O}\right)$ between two materials $\left(\mu_{O}^{I}<\mu_{O}^{I I}\right)$ may give rise to charged ionic transfer to bring the equilibrium of the system with heterogeneous junction at the interface (Fig. 1a) ${ }^{5,8-12}$. In particular, charged ionic defects migrate by ionic diffusion (e.g., diffusion of oxygen ions through vacancies) to mitigate $\Delta \mu_{O}$ at the interface; ${ }^{9-14}$ charged ions, in principle, are transferred to adjacent materials and reconfigured by the redox reaction across the chemically-reacting interfaces in oxide heterostructure until the chemical potentials of the layers match $\left(\mu_{O}^{I}=\mu_{O}^{I I} \text { in Fig. } 1 \mathrm{a}\right)^{5}$.

For example, the vanadium dioxide $\left(\mathrm{VO}_{2}\right)$, the archetypal correlated oxide with metal-insulator (MI) transition near room temperature, is interfaced with ionic liquid (IL), and then (electro-)chemical potential can be adjusted by applying an external electric field across the $\mathrm{VO}_{2} / \mathrm{IL}$ interfaces $9,14-16$. In this case, instead of electric charge transfer, charged oxygen ions outdiffused to the IL to equilibrate the (electro-)chemical potential between $\mathrm{VO}_{2}$ and $\mathrm{IL}$; the formation of oxygen vacancies $\left(V_{\mathrm{O}}\right)$ by oxygen ion migration are responsible for the reversible insulatorto-metal transition and giant lattice expansion in $\mathrm{VO}_{2}$ films under the positive bias ${ }^{15}$. Furthermore, $V_{O}$ concentrations that develop in $\mathrm{LaNiO}_{3}, \mathrm{LaTiO}_{3}$, and $\mathrm{In}_{2} \mathrm{O}_{3}$ can be modulated by the directional oxygen flow to the adjacent layers ${ }^{10-12}$.

At interfaces where ionic flux $\left(J_{O^{2-}}\right.$ in Fig. 1a) is directional, the dynamics of charged ions may be important by assembling other metal oxides that have different $\mu_{O} 10,11,14$. The redistribution of charged vacancies can screen the electric fields that $\Delta \mu_{O}$ causes. Therefore, the massive redistribution of charged ions can be accelerated by extremely increasing the thermodynamic $\Delta \mu_{O}$ across the interfaces; by supplying unidirectional charged ionic flux, this redistribution may offer a spontaneous route that can facilitate synthesis of crystalline materials ${ }^{12}$, and may enable robust control of defect-induced properties at oxide interfaces ${ }^{9,13,14}$.

Here, we demonstrate the formation of high-quality rutile $\mathrm{TiO}_{2}$ epitaxial films at exceptionally low temperature, which is driven by directional transport of oxygen ions across the $\mathrm{TiO}_{2} / \mathrm{VO}_{2}$ heterointerfaces. Contrary to the amorphous nature of $\mathrm{TiO}_{2}$ films directly grown on $\mathrm{TiO}_{2}$ substrates at $150{ }^{\circ} \mathrm{C}$, single-crystal rutile $\mathrm{TiO}_{2}$ layer is synthesized by forming the heterointerface with $\mathrm{VO}_{2}$ template at the lowest growth temperature $T_{\mathrm{G}}\left(<150^{\circ} \mathrm{C}\right)$ ever reported, at which rutile $\mathrm{TiO}_{2}$ is difficult to be crystallized. By a
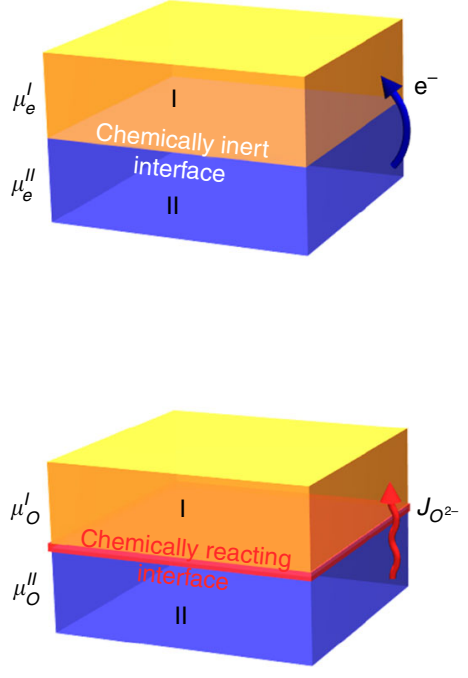

$J_{O^{2-}}=k \times f\left[\Delta \mu_{0}\right]$ b

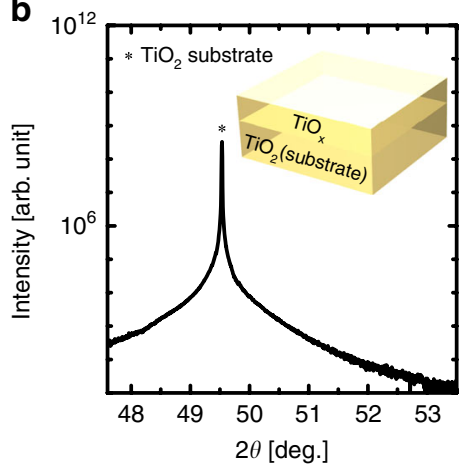

d

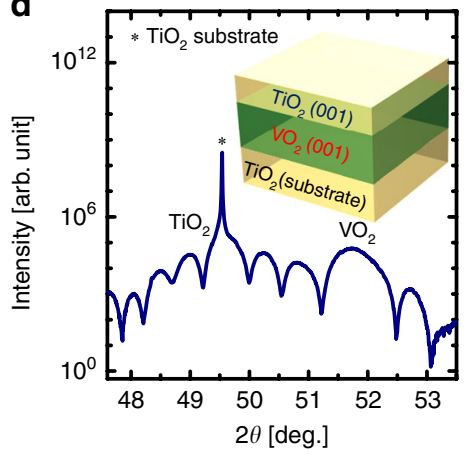

C

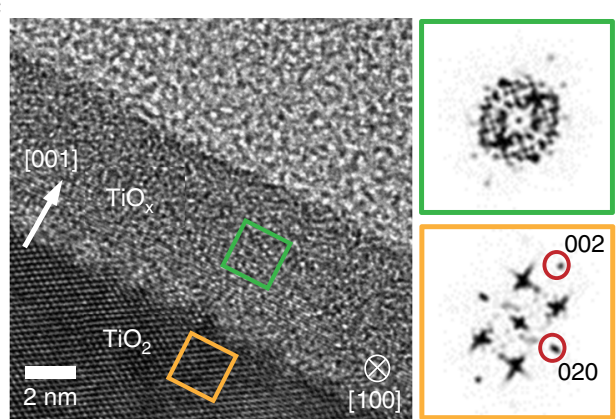

e
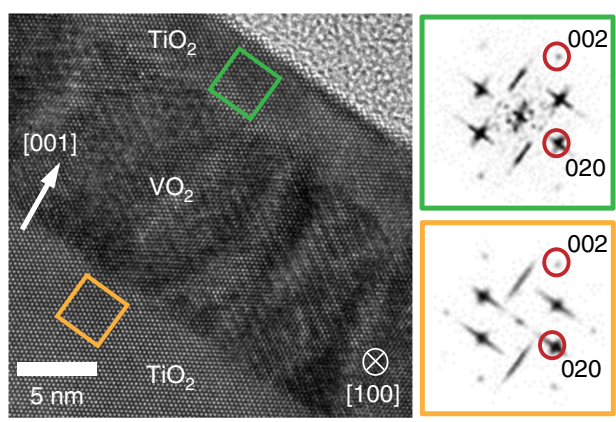

Fig. 1 Low-temperature epitaxy of rutile $\mathbf{T i O}_{\mathbf{2}}$ on $\mathbf{V O}_{\mathbf{2}}$ sacrificial templates. a Schematics of possible directional charge (top) and ionic (bottom) transport due to chemical potential mismatch $(\Delta \mu)$ across the interface with loss of translational symmetry. Symmetrical $\mathrm{x}$-ray scan of $\mathbf{b} \mathrm{TiO} \times / \mathrm{TiO}{ }_{2}$ homostructure and $\mathbf{d} \mathrm{TiO}_{2} / \mathrm{VO}_{2} / \mathrm{TiO}_{2}$ heterostructure containing $\mathrm{TiO}_{2}$ films grown at $150{ }^{\circ} \mathrm{C}$. Contrary to the absence of peak around $\mathrm{TiO}_{2}$ substrate peak in homostructure (b), (002) Bragg reflections and Kiessig fringes around the peak from $\mathrm{TiO}_{2}$ substrate in heterostructure in $\mathbf{d}$ indicate that the $\mathrm{TiO}_{2}$ films are epitaxially grown at $150^{\circ} \mathrm{C}$ on $\mathrm{VO}_{2}$ templates with sharp interface. HRTEM images and FFT patterns of $\mathbf{c} \mathrm{TiO}_{\times} / \mathrm{TiO}_{2}$ homostructure (scale bar $=2 \mathrm{~nm}$ ) and e. $\mathrm{TiO}_{2} / \mathrm{VO}_{2} / \mathrm{TiO}_{2}$ heterostructure (scale bar $=5 \mathrm{~nm}$ ) projected with [100] zone axis. Unlike the amorphous nature of $\mathrm{TiO}_{x}$ films in homostructures (green square in c), obvious diffraction spots were observed in the FFT pattern of the $\mathrm{TiO}_{2}$ films on $\mathrm{VO}_{2} / \mathrm{TiO}_{2}$ (green square in e), and were same as those observed from the $\mathrm{TiO}_{2}$ substrates (yellow square in e); this similarity indicates an identical epitaxial relationship of $\mathrm{TiO}_{2}$ epitaxial films with $\mathrm{TiO}_{2}$ substrates in $\mathrm{TiO}_{2} / \mathrm{VO}_{2} / \mathrm{TiO}_{2}$ heterostructure. 
experimental characterization using atomic-resolution electron microscopy and synchrotron x-ray spectroscopy combined with theoretical calculation, we demonstrate that a facile ionic diffusion of oxygen ions from the oxygen reservoir $\mathrm{VO}_{2}$ along the [001] channel decreases $\Delta \mu_{O}$, and thereby enables this unprecedented epitaxy of rutile $\mathrm{TiO}_{2}$ at low temperature by lowering the activation barrier for formation of stable nuclei. Interestingly, this directional ionic transport improves the registry in the lattice of $\mathrm{TiO}_{2}$ films at the expense of the structural and electronic modulation in an oxygen-deficient $\mathrm{VO}_{2-\delta}$ sacrificial layer. As a result of the mismatch of thermodynamic driving force combined with kinetically-facile migration of oxygen ions across the $\mathrm{TiO}_{2} / \mathrm{VO}_{2}$ interfaces, the massive redistribution of oxygen ions enables lowtemperature epitaxy of high-temperature-stabilized phase by increasing an "internal" oxygen supply across the chemicallyreacting oxide interface.

\section{Results}

Low temperature epitaxial growth of rutile $\mathrm{TiO}_{2}$ films on $\mathrm{VO}_{2}$ template. Prior to $\mathrm{TiO}_{2}$ growth, the substrates with $12-\mathrm{nm}$ thick $\mathrm{VO}_{2}$ template were prepared on (001)-oriented $\mathrm{TiO}_{2}$ substrates by pulsed laser deposition (Supplementary Fig. 1). X-ray diffraction (XRD) results (Supplementary Fig. 2a) showed sharp $\mathrm{VO}_{2}(002)_{\mathrm{R}}$ peaks (in rutile notation) at $\sim 2 \theta=65.9^{\circ}(c=$ $0.2839 \mathrm{~nm}$ ) without other peaks related to vanadium oxides that had valence states other than +4 . A steep MI transition $\left(\Delta R_{S} \sim 10^{3.3}\right)$ occurred on the $\mathrm{VO}_{2}$ films at $T_{M I} \sim 298 \mathrm{~K}$ (Supplementary Fig. 2b); this result indicates the formation of coherently tensile-strained $\mathrm{VO}_{2}$ films with high crystal quality and negligible $V_{O}^{9,15,17,18}$.

Then, the $6 \mathrm{~nm}$-thick $\mathrm{TiO}_{2}$ films were grown at low $T_{\mathrm{G}} \sim 150^{\circ} \mathrm{C}$ with the same oxygen pressure $\left(\mathrm{pO}_{2} \sim 12\right.$ mTorr $)$ on two substrates: 1) (001) $\mathrm{TiO}_{2}$ single crystals without the $\mathrm{VO}_{2}$ template layer (denoted as $\mathrm{TiO}_{2} / \mathrm{TiO}_{2}$ hereafter) and 2) (001) $\mathrm{TiO}_{2}$ single crystals with the $\mathrm{VO}_{2}$ template (denoted as $\mathrm{TiO}_{2} / \mathrm{VO}_{2} / \mathrm{TiO}_{2}$ ). Symmetric $2 \theta-\omega$ scans using synchrotron X-ray scattering on $\mathrm{TiO}_{2} / \mathrm{TiO}_{2}$ grown at $T_{\mathrm{G}}=150^{\circ} \mathrm{C}$ (Fig. 1b) detected no Bragg reflections except for substrate $\left(2 \theta=49.54^{\circ}\right)$; this absence indicates no formation of crystalline $\mathrm{TiO}_{2}$ films ${ }^{16}$; the formation of amorphous $\mathrm{TiO}_{2}$ films on $\mathrm{TiO}_{2}$ substrates is attributed to the thermodynamic or kinetic instability of the rutile $\mathrm{TiO}_{2}$ phase, which requires sufficient thermal energy for phase formation ${ }^{19-23}$. To exclude the possible coincidence of diffraction peak from $\mathrm{TiO}_{2}$ films and substrates in homostructures in Fig. 1b, $\mathrm{TiO}_{2}$ films were also grown on (100) $\mathrm{Al}_{2} \mathrm{O}_{3}$ single crystal substrates (Supplementary Fig. 3). The symmetric $2 \theta-\omega$ scan in wide range of angle also detected the only peak related to the (100) $\mathrm{Al}_{2} \mathrm{O}_{3}$ substrate $\left(2 \theta=68.22^{\circ}\right)$ due to the formation of amorphous films at $T_{\mathrm{G}}=150^{\circ} \mathrm{C}$.

In contrast, rutile $\mathrm{TiO}_{2}$ epitaxial films were strikingly stabilized by introducing the $\mathrm{VO}_{2}$ layers on $\mathrm{TiO}_{2}$ substrate at the same condition with $T_{\mathrm{G}}=150^{\circ} \mathrm{C}$. Symmetric $2 \theta-\omega$ scans of $\mathrm{TiO}_{2} / \mathrm{VO}_{2} /$ $\mathrm{TiO}_{2}$ heterostructures (Fig. 1d) showed two Bragg reflections, one from the rutile $\mathrm{TiO}_{2}\left(2 \theta=49.46^{\circ}\right)$ substrates, and one from $\mathrm{VO}_{2}$ $\left(2 \theta=51.8^{\circ}\right)$ films. More importantly, the $\mathrm{TiO}_{2}$ substrate peak was resolved to a slightly broad peak from $\mathrm{TiO}_{2}$ epitaxial films ${ }^{16}$, which did not appear in the scans of $\mathrm{TiO}_{2} / \mathrm{TiO}_{2}$ homostructure. Each film peak exhibited a Kiessig fringe; fitting of the peaks showed that their periodicity differed due to different film thickness (Supplementary Fig. 4); these clear oscillations from peaks represent sharp interface of $\mathrm{TiO}_{2} / \mathrm{VO}_{2} / \mathrm{TiO}_{2}$ all-epitaxial heterostructures.

The low-temperature epitaxy of rutile $\mathrm{TiO}_{2}$ films on $\mathrm{VO}_{2}$ templated substrates was locally visualized by comparing crosssection high-resolution transmission electron microscope (HRTEM) images of both $\mathrm{TiO}_{x}(x<2) / \mathrm{TiO}_{2}$ and $\mathrm{TiO}_{2} / \mathrm{VO}_{2} / \mathrm{TiO}_{2}$ (Fig. 1c, e). Amorphous nature of $\mathrm{TiO}_{\mathrm{x}}$ films on $\mathrm{TiO}_{2}$ was confirmed by the diffused halo feature in fast Fourier transform (FFT) pattern from the films (green square in the right column of Fig. 1c). In contrast, sharp diffraction spots were observed in FFT pattern of the $\mathrm{TiO}_{2}$ films on $\mathrm{VO}_{2} / \mathrm{TiO}_{2}$ (green square in the right column of Fig. 1e), and is similar with that from the $\mathrm{TiO}_{2}$ substrates (yellow square in the right column of Fig. 1e); this observation demonstrates that epitaxial rutile $\mathrm{TiO}_{2}$ films can be crystallized at $150^{\circ} \mathrm{C}$ simply by introducing $\mathrm{VO}_{2}$ templates on $\mathrm{TiO}_{2}$ substrate. Considering the dramatic difference of crystallinity in those $\mathrm{TiO}_{2}$ films grown at the same growth condition, the epitaxial $\mathrm{TiO}_{2}$ with excellent crystallinity at $150{ }^{\circ} \mathrm{C}$ is unusual, because it formed even though thermal energy was insufficient at $150{ }^{\circ} \mathrm{C}$ to overcome the activation energy that is required to drive formation of thermodynamically stable crystalline nuclei ${ }^{20,23}$.

To determine how this unprecedented rutile $\mathrm{TiO}_{2}$ phase developed low-temperature epitaxy, annular bright field (ABF) scanning transmission electron microscopy (STEM) data were analyzed with $\mathrm{TiO}_{2} / \mathrm{VO}_{2} / \mathrm{TiO}_{2}$ heterostructure. The sensitivity of $\mathrm{ABF}$ to light-weight atoms permitted visualization of oxygen atomic columns in ABF STEM (Fig. 2a) ${ }^{17}$. Magnified ABF-STEM images (red rectangles) show the typical rutile $\mathrm{TiO}_{2}$ structure in both film and substrate; this result indicates that $\mathrm{TiO}_{2}$ films had been fully crystallized by coherent epitaxial growth on $\mathrm{VO}_{2}$ templates. However, the contrasts of oxygen atomic columns in $\mathrm{VO}_{2}$ are weak and diffuse in the enlarged images of $\mathrm{VO}_{2}$ (blue rectangle); this result implies that oxygen contents are deficient in the $\mathrm{VO}_{2}$ template after low-temperature epitaxy of stoichiometric rutile $\mathrm{TiO}_{2}$ films. Therefore, $\mathrm{TiO}_{2}$ films with perfect registry of atoms were epitaxially grown on top of defective $\mathrm{VO}_{2}$ templates; this result is contrary to the general principle that high-quality epitaxial growth is achieved by using low-defect substrates, and suggests that the chemical reaction at the interface is likely to facilitate the low-temperature epitaxy of high-quality $\mathrm{TiO}_{2}$ films by sacrificing the initially good quality of $\mathrm{VO}_{2}$ templates.

The formation of defective features in $\mathrm{VO}_{2}$ template could be confirmed by comparing high-angle annular dark field (HAADF) and low-angle annular dark field (LAADF) signals of $\mathrm{TiO}_{2} / \mathrm{VO}_{2} /$ $\mathrm{TiO}_{2}$ heterostructures from STEM. Contrary to almost identical HAADF contrast across the heterostructures due to similar cation atomic weight across the heterostructures ${ }^{16}$ (Fig. 2b), the LAADF contrast was noticeably mottled in $\mathrm{VO}_{2}$ templates (Fig. 2c) that were sandwiched between $\mathrm{TiO}_{2}$ films and substrates. The HAADF and LAADF images had distinct intensity profiles along the film growth direction of [001] (insets in Fig. 2b, c) The differences occur because the LAADF signal is more sensitive than the HAADF signal to the frustrated atomic channeling due to oxygen vacancies $\left(V_{O}\right)^{4,24}$, so the contrast is blurred and brighter in the LAADF signal of $\mathrm{VO}_{2}$ templates. Moreover, electron energy loss spectroscopy (EELS) experiments reveal that the $t_{2 \mathrm{~g}}$ peak of $\mathrm{O}-K$ edge was strongly suppressed in the entire $\mathrm{VO}_{2}$ template (Supplementary Fig. 5b); this result directly visualize the formation of oxygen vacancies ${ }^{25}$. Therefore, the combined results from LAADF contrast and EELS data in $\mathrm{VO}_{2}$ templates confirms the significant loss of oxygen atoms from $\mathrm{VO}_{2}$ during the low-temperature epitaxial growth of $\mathrm{TiO}_{2}$ films in the heterostructures.

Suppression of metal-insulator transition in $\mathrm{VO}_{2}$ templates by directional oxygen transport. Interestingly, the degree of oxygen deficiency of $\mathrm{VO}_{2}$ templates was sensitively modulated by adjusting $\mathrm{pO}_{2}$ (6 mTorr $\left.\sim 24 \mathrm{mTorr}\right)$ during $\mathrm{TiO}_{2}$ growth at $T_{\mathrm{G}} \sim$ $150{ }^{\circ} \mathrm{C}$ on $\mathrm{VO}_{2}$-templated $\mathrm{TiO}_{2}$ substrates. As observed in symmetric $2 \theta-\omega$ synchrotron XRD scans in all heterostructures, Bragg 
a

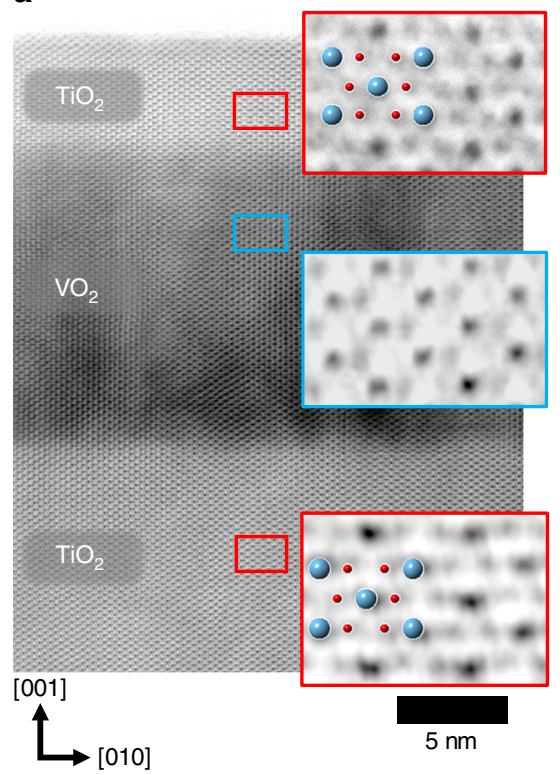

b

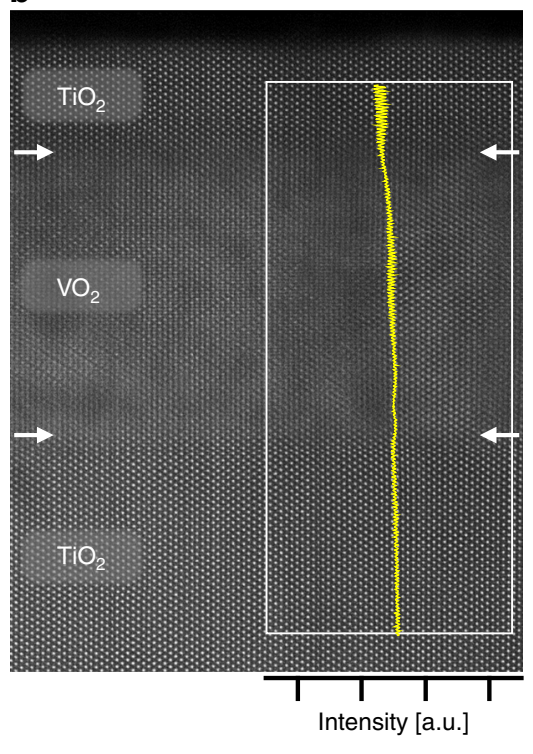

c

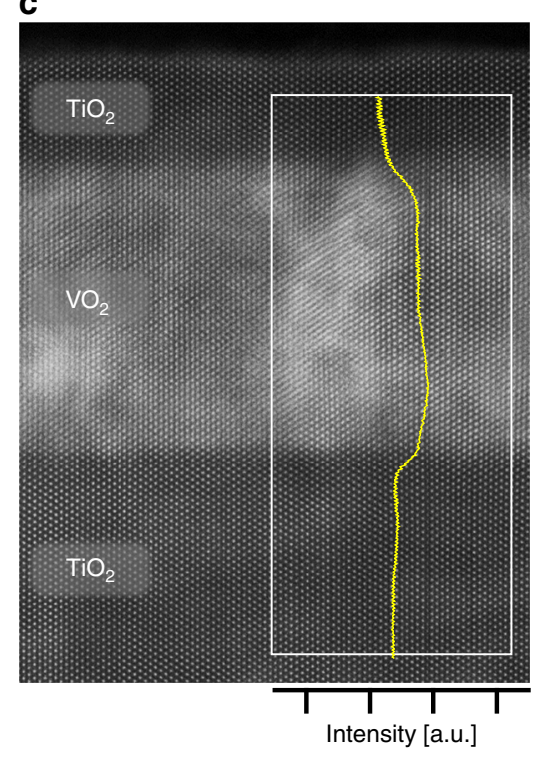

Fig. 2 Atomic-resolution analysis of $\mathrm{TiO}_{2} / \mathbf{V O}_{\mathbf{2}} / \mathrm{TiO}_{\mathbf{2}}$ heterostructure. a ABF-STEM, b HAADF-STEM and $\mathbf{c} L A A D F-S T E M$ images of rutile TiO 2 epitaxial film grown on $\mathrm{VO}_{2}$ sacrificial template at $T_{\mathrm{G}}=150{ }^{\circ} \mathrm{C}$ with [100] zone axis (scale bar $=5 \mathrm{~nm}$ ). The sensitivity of $A B F$ technique to light-weight atoms enables observation of oxygen atoms along the $[100]$ zone axis. Note that the regular pattern from $\mathrm{TiO}_{2}$ epitaxial films (top red square in a) was identical to that from $\mathrm{TiO}_{2}$ substrates (bottom red square in $\mathbf{a}$ ), indicating an identical atomic arrangement of films with single crystals by epitaxial growth without oxygen defects. On the contrary, the oxygen-deficient region was observed in the sacrificed $\mathrm{VO}_{2}$ template near the $\mathrm{TiO}_{2}$ film (blue square in a). While almost-uniform HAADF contrast was observed across the heterostructures due to similar cation atomic weight across the heterostructures (b), a noticeable strain-field-induced LAADF contrast was observed in $\mathrm{VO}_{2}$ templates (c) sandwiched between $\mathrm{TiO}_{2}$ films and substrates. Yellow lines in $\mathbf{b}$ and c are the contrast-intensity profiles of the HAADF and LAADF images from the white rectangular areas.

peaks and Kiessig fringes from $\mathrm{TiO}_{2}$ films were resolved from those from $\mathrm{TiO}_{2}$ substrates and $\mathrm{VO}_{2}$ templates with different period of oscillations in fringes (Fig. 3a), which again confirms the importance of $\mathrm{VO}_{2}$ templates for low-temperature epitaxy of $\mathrm{TiO}_{2}$ layers. However, unlike the almost identical peak of $\mathrm{TiO}_{2}$ films and substrates, the (002) reflection of 14-nm-thick $\mathrm{VO}_{2}$ template films decreased from $2 \theta=51.9^{\circ}$ (black) to $2 \theta=51.5^{\circ}$ (green) from symmetric $2 \theta-\omega$ scans as $p \mathrm{O}_{2}$ was reduced from 24 mTorr to 6 mTorr during the $\mathrm{TiO}_{2}$ growth (Fig. 3a); this peak shift corresponds to $\sim 0.8 \%$ expansion of the out-of-plane lattice parameters in $\mathrm{VO}_{2}$ templates.

For more detailed structural modulation of $\mathrm{TiO}_{2} / \mathrm{VO}_{2} / \mathrm{TiO}_{2}$ heterostructures, reciprocal space mapping (RSM) around the (112) reflection of (001) $\mathrm{TiO}_{2}$ substrate was performed to obtain the information on both in-plane and out-of-plane lattice parameters by adjusting $p \mathrm{O}_{2}$ during $\mathrm{TiO}_{2}$ growth (Fig. 3b). The RSM data of all heterostructures clearly show sharp and intense (112) Bragg reflections and Kiessig fringes from $\mathrm{TiO}_{2}$ substrate and film, and from the $\mathrm{VO}_{2}$ films. The substrate and film peaks showed identical H (i.e., in-plane reciprocal space unit) ${ }^{26,27}$, which implicates that entire layers in all heterostructures are coherently strained by $\mathrm{TiO}_{2}$ substrates along the in-plane direction. Geometric phase analysis (GPA) strain quantification using obtained STEM image confirms coherent interfaces through the heterostructures (Supplementary Fig. 6). However, only the $\mathrm{VO}_{2}$ peak shifted to lower scattering angle (i.e., characteristic of expansion of out-of-plane lattice parameters) as the $\mathrm{pO}_{2}$ during $\mathrm{TiO}_{2}$ growth was decreased; these trends are consistent with vanadium valence state switching $\left(\mathrm{V}^{4+}\right.$ to $\left.\mathrm{V}^{3+}\right)$ by the formation of $V_{O}$ in $\mathrm{VO}_{2}$ templates ${ }^{15,16,28}$.

Temperature-dependent sheet resistance $R_{\mathrm{S}}(\mathrm{T})$ of $\mathrm{TiO}_{2} / \mathrm{VO}_{2} /$ $\mathrm{TiO}_{2}$ heterostructures (by van der Paw methods) was measured to quantify how the accelerated oxygen deficiency in $\mathrm{VO}_{2}$ templates affected electrical transport of the heterostructures (Fig. 3c). The heterostructure that had been formed using $p \mathrm{O}_{2} \sim 24 \mathrm{mTorr}$ during $\mathrm{TiO}_{2}$ growth (denoted as $\mathrm{H} 24 \mathrm{mT}$ hereafter) exhibited slightly suppressed MI transition in terms of $R_{S}(\mathrm{~T})$ (i.e., 3.2 orders of magnitude at $T_{M I} \sim 298 \mathrm{~K}$ ) compared with as-grown $\mathrm{VO}_{2}$ films without $\mathrm{TiO}_{2}$ layers on top. On the contrary, $R_{\mathrm{S}}(\mathrm{T})$ of the heterostructure with $\mathrm{pO}_{2}$ of $6 \mathrm{mTorr}$ (denoted as $\mathrm{H} 6 \mathrm{mT}$ ) substantially dropped by just less than an order of magnitude; This result indicates that MI transition of $\mathrm{VO}_{2}$ templates was progressively suppressed and $T_{M I}$ was monotonically decreased from $298 \mathrm{~K}(\mathrm{H} 24 \mathrm{mT})$ to $260 \mathrm{~K}(\mathrm{H} 6 \mathrm{mT})$ by the gradual increase of $V_{\mathrm{O}}$ in $\mathrm{VO}_{2}$ as the $\mathrm{TiO}_{2}$ films were grown at progressively lower $p \mathrm{O}_{2}$ (Fig. 3d ${ }^{4,9}$. As a result, the formation of $V_{O}$ by oxygen ionic transfer across the interface not only expanded the lattice to compensate for the larger cation radius of $\mathrm{V}^{3+}\left(3 d^{2}\right)$ than $\mathrm{V}^{4+}$ $\left(3 d^{1}\right)^{28}$, but also induced the metallic state at $\mathrm{TiO}_{2} / \mathrm{VO}_{2}$ interfaces even at $270 \mathrm{~K}$ (Fig. 3e). Structural and electrical modulation driven by $V_{O}$ in $\mathrm{VO}_{2}$ cannot be generated by simple post-annealing without $\mathrm{TiO}_{2}$ layer growth on top; directional oxygen ionic transport indeed occurs across the $\mathrm{TiO}_{2} / \mathrm{VO}_{2}$ interfaces by forming $V_{O}$ in $\mathrm{VO}_{2}$ layer, as long as $\mathrm{TiO}_{2}$ layers are grown on $\mathrm{VO}_{2}$ templates (Supplementary Fig. 14).

To elucidate the origin of metallicity in a $\mathrm{VO}_{2}$ template interfaced with a $\mathrm{TiO}_{2}$ layer, we performed polarization-

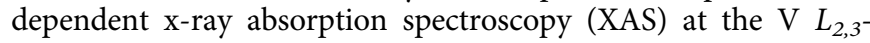
edges for two heterostructures that contained 2.5-nm-thick $\mathrm{TiO}_{2}$ films grown on $\mathrm{VO}_{2}$ templates under $\mathrm{pO}_{2}=24 \mathrm{mTorr}(\mathrm{H} 24 \mathrm{mT}$, Fig. 4a) and 6 mTorr (H6mT, Fig. 4b). The XAS signals at the V $L_{2,3}$-edges represent a dipole-allowed transition from the V $2 p_{1 / 2}$ and $2 p_{3 / 2}$ core level to the $\mathrm{V} 3 d$ valence electronic states (i.e., $\left.2 p^{6} 3 d^{1} \rightarrow 2 p^{5} 3 d^{2}\right)^{29-31}$ only from the $\mathrm{VO}_{2}$ templates buried under layers of rutile $\mathrm{TiO}_{2}$ owing to its element-specific character. Linearly-polarized $\mathrm{X}$-rays with the polarization vector 


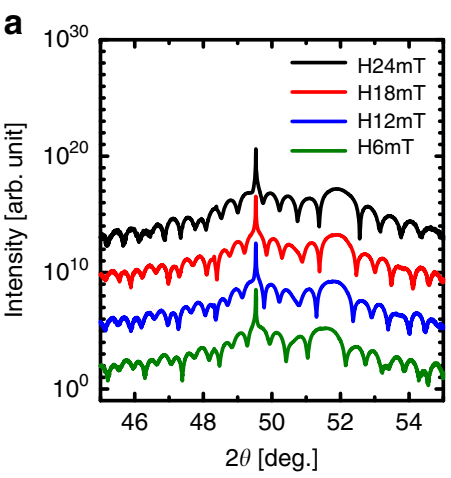

C

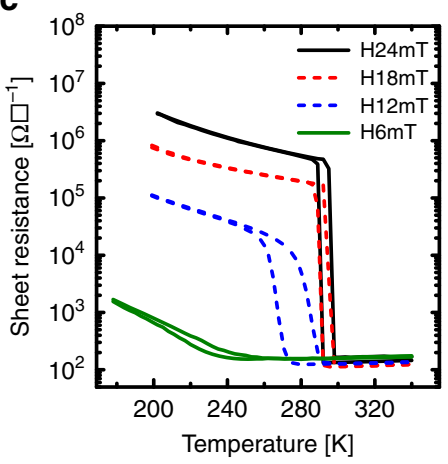

b
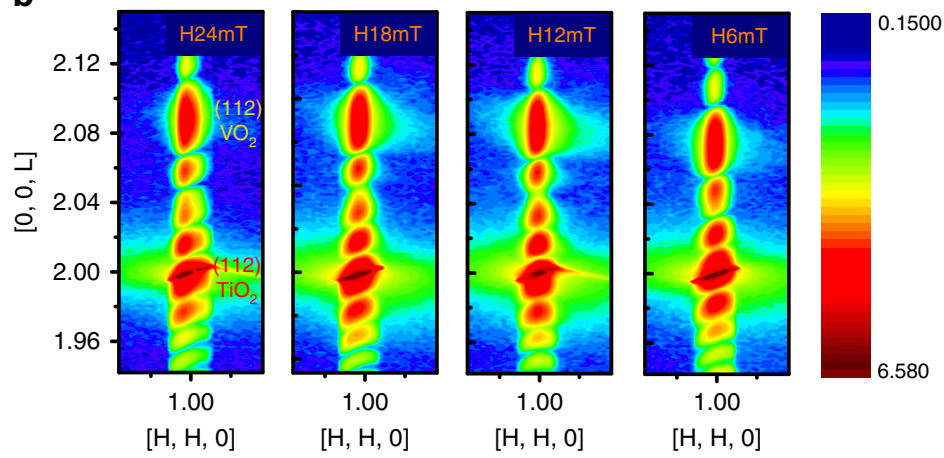

d
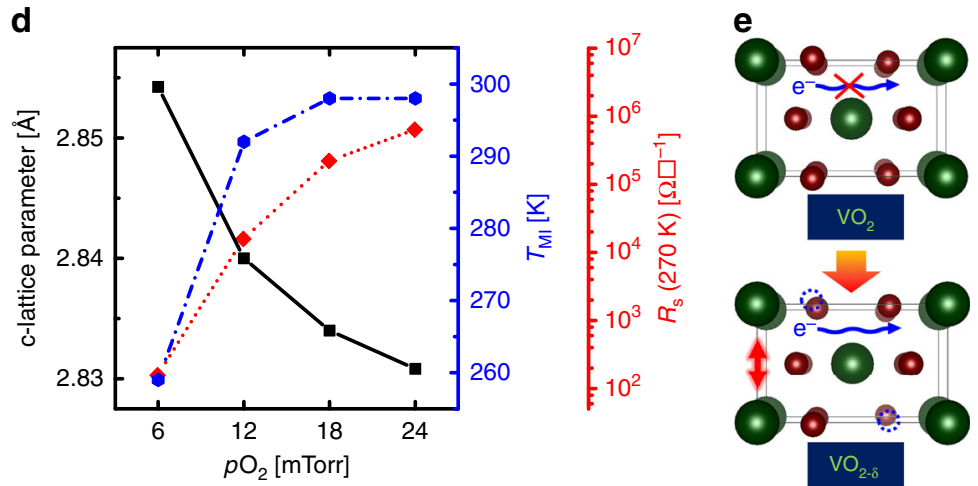

Fig. 3 Structural/electronic modulation by directional ionic transport. a Symmetrical X-ray scan and $\mathbf{b}$ reciprocal space mapping around (112) reflection of $\mathrm{TiO}_{2}$ grown under $\mathrm{pO}_{2}=6 \mathrm{mTorr}$ (denoted as $\mathrm{H6mT}$ ) $\sim 24 \mathrm{mTorr}$ (denoted as $\mathrm{H} 24 \mathrm{mT}$ ) on $\mathrm{VO}_{2}$-templated TiO ${ }_{2}$ substrates. These results confirm that entire layers in all heterostructures are coherently strained by $\mathrm{TiO}_{2}$ substrates, but only $\mathrm{VO}_{2}$ peaks shifted to lower scattering angles as $p \mathrm{O}_{2}$ decreased during $\mathrm{TiO}_{2}$ growth. c Temperature-dependent sheet resistance $\left(R_{\mathrm{S}}\right)$ in all $\mathrm{TiO}_{2} / \mathrm{VO}_{2} / \mathrm{TiO}_{2}$ heterostructures with $\mathrm{TiO}_{2}$ epitaxial films grown at $6 \leq p \mathrm{O}_{2} \leq$ 24 mTorr on $\mathrm{VO}_{2}$-templated $\mathrm{TiO}_{2}$ substrates. $\mathbf{d}$ Lattice parameter (c) from a and temperature $\left(T_{\mathrm{MI}}\right)$ of metal-insulator transition and $R_{\mathrm{S}}$ at $270 \mathrm{~K}$ from $\mathbf{c}$ as a function of $\mathrm{pO}_{2}$ during $\mathrm{TiO}_{2}$ growth. e The formation of oxygen vacancies in $\mathrm{VO}_{2}$ by ionic transfer across the $\mathrm{TiO}_{2} / \mathrm{VO}_{2}$ interface expanded the lattice to compensate for the larger cation radius of $\mathrm{V}^{3+}\left(3 d^{2}\right)$ than $\mathrm{V}^{4+}\left(3 d^{1}\right)$, and also led to the oxygen-vacancy-induced metallization.

parallel $(\mathbf{E} \| c)$ and perpendicular $(\mathbf{E} \perp \mathbf{c})$ to the out-of-plane orientation ( $c$ axis), respectively, detect the vacant $d_{\|}$and $\pi^{*}$ electron $\operatorname{states}^{31}$, so $V_{O}$ formation also significantly affects the dichroic signal (Fig. 4a, b) related to selective orbital occupancy of $d_{\|}$induced by V-V dimerization ${ }^{30,31}$.

In $\mathrm{H} 24 \mathrm{mT}$ sample, XAS spectra collected at $320 \mathrm{~K}\left(T>T_{M I}\right)$ were similar regardless of the polarization direction of the X-ray (Supplementary Fig. 7a); this result was expected because of the isotropic orbital filling in the metallic states of $\mathrm{VO}_{2}$ due to absence of $\mathrm{V}-\mathrm{V}$ dimerization. At $270 \mathrm{~K}\left(T<T_{M I}\right.$, Fig. $\left.3 c\right)$, X-ray linear dichroism (XLD, $I_{\|}-I_{\perp}$ ) was much larger than at $T=320 \mathrm{~K}$ (Fig. 4a, c); this increase is a signature of orbital polarization, which is expected to result from the strong $\mathrm{V}-\mathrm{V}$ dimerization in the insulating states, due to the selective filling of $d_{\|}$orbitals in $\mathrm{VO}_{2}$ films with negligible oxygen loss (inset, Fig. 4c) $)^{30,31}$. In contrast, XAS spectra of H6mT, which is the sample with the highest driving force for oxygen ion transport from $\mathrm{VO}_{2}$ sacrificial template, show no polarization-dependence of incident X-ray (Fig. 4d) at either $T=270 \mathrm{~K}$ (Fig. $4 \mathrm{~b}$ ) or $320 \mathrm{~K}$ (Supplementary Fig. 7b). This result indicates that selective filling of $d_{\|}$orbitals did not occur below $270 \mathrm{~K}^{30,31}$ and explains the $V_{O}$-induced metallic behavior at $270 \mathrm{~K}$ in $\mathrm{H} 6 \mathrm{mT}$ : $V_{O}$ tends to increase the crystal symmetry toward thermally-induced tetragonal rutile structure by weakening of $\mathrm{V}-\mathrm{V}$ dimerization ${ }^{15,32,33}$ and leads to isotropic orbital occupancy of $d_{\|}$and $\pi^{* 33}$, (inset of Fig. $4 \mathrm{~d}$ ). The absence of selective filling in $d_{\|}$orbitals in H6mT samples provides strong evidence for $V_{O}$ formation in the entire area of sacrificial $\mathrm{VO}_{2}$ templates by directional oxygen transport from $\mathrm{VO}_{2}$ to $\mathrm{TiO}_{2}$.
Stoichiometric $\mathrm{TiO}_{2}$ epitaxy induced by directional oxygen transport. To explore the influence of directional ionic transport on the quality of $\mathrm{TiO}_{2}$ epitaxial layer grown at $T_{G} \sim 150{ }^{\circ} \mathrm{C}$, we evaluated the element-specific Ti $L_{2,3}$-edge XAS signal from the $\mathrm{TiO}_{2}$ layer in $\mathrm{TiO}_{2} / \mathrm{VO}_{2}$ heterostructures. The $\mathrm{Ti} L_{3}$ edge peak between $457.9 \mathrm{eV} \sim 461.3 \mathrm{eV}$ (i.e., related to $e_{\mathrm{g}}$ orbitals) is split into two peaks due to the distortion of the $\mathrm{TiO}_{6}$ octahedra in rutile structure; the relative intensities of these $e_{\mathrm{g}}$ doublet $\left(e_{\mathrm{g}}{ }^{1}<\right.$ $e_{\mathrm{g}}^{2}$ ) verified a rutile $\mathrm{TiO}_{2}$ phase in both $\mathrm{H} 24 \mathrm{mT}$ and $\mathrm{H} 6 \mathrm{mT}$ films ${ }^{34,35}$ (Fig. 5a), which is consistent with our results in HRXRD and STEM. The Ti $L_{2,3}$-edge signals from $\mathrm{H} 6 \mathrm{mT}$ were more intense and sharper than from $\mathrm{H} 24 \mathrm{mT}^{36,37}$. Furthermore, the contribution of $\mathrm{Ti}^{3+} L$-edge signals slightly increased the dips at $458 \mathrm{eV}$ and $461 \mathrm{eV}$ in the $\mathrm{H} 24 \mathrm{mT}$ relative to those in $\mathrm{H} 6 \mathrm{mT}$ (inset of Fig. 5a, yellow arrow); ${ }^{36}$ these results reveal that rutile $\mathrm{TiO}_{2}$ films toward the stoichiometry with low oxygen deficiency can be formed more easily by the $\mathrm{TiO}_{2}$ growth with low $p \mathrm{O}_{2}$ than with high $\mathrm{pO}_{2}$. Moreover, EELS data from the top $\mathrm{TiO}_{2}$ layers in $\mathrm{H} 6 \mathrm{mT}$ show that the $t_{2 \mathrm{~g}}$ peaks of $\mathrm{Ti}-L$ edge from $\mathrm{TiO}_{2}$ layers is exactly same as those from stoichiometric bulk $\mathrm{TiO}_{2}$ substrates (reference) (Supplementary Fig. 5c); this result represents the formation of stoichiometric $\mathrm{TiO}_{2}$ layers at the expense of oxygen deficiency in $\mathrm{VO}_{2}$ layers.

In addition to bulk-sensitive XAS and EELS, X-ray photoelectron spectroscopy (XPS) of the Ti $2 p$ core level shows better stoichiometry of rutile $\mathrm{TiO}_{2}$ film surface grown on $\mathrm{VO}_{2}$ templates under low $\mathrm{pO}_{2}$ than under high $\mathrm{pO}_{2}$ (Fig. 5b). Deconvolution of The Ti $2 \mathrm{p}$ core-level peaks with $\mathrm{Ti}^{4+}\left(2 p_{3 / 2} \sim 458.8 \mathrm{eV}, 2 p_{1 / 2} \sim\right.$ $464.6 \mathrm{eV})$ and $\mathrm{Ti}^{3+}\left(2 p_{3 / 2} \sim 457.2 \mathrm{eV}, 2 p_{1 / 2} \sim 463.1 \mathrm{eV}\right)$ valence 
a

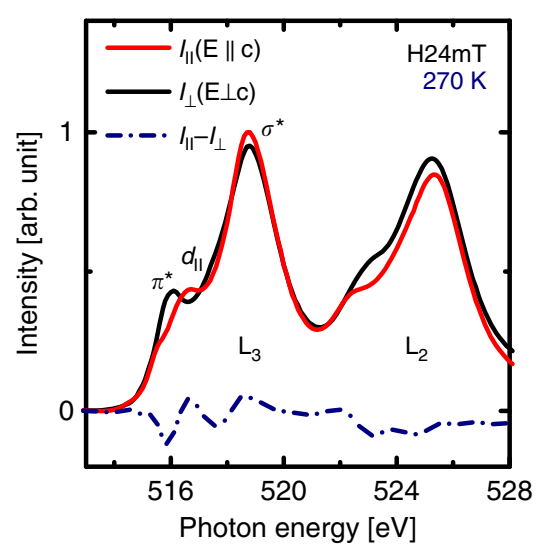

b

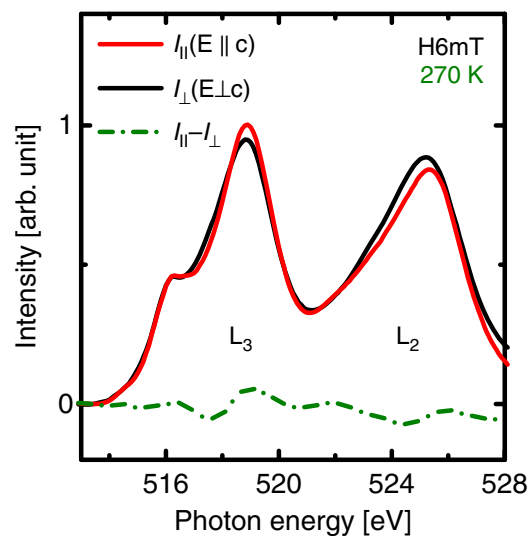

c

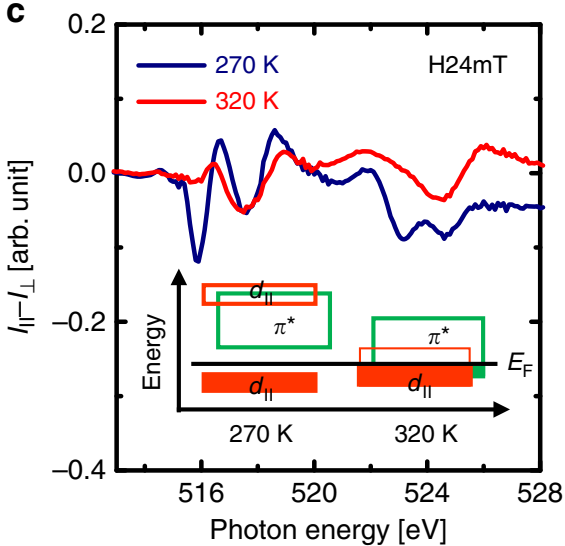

d

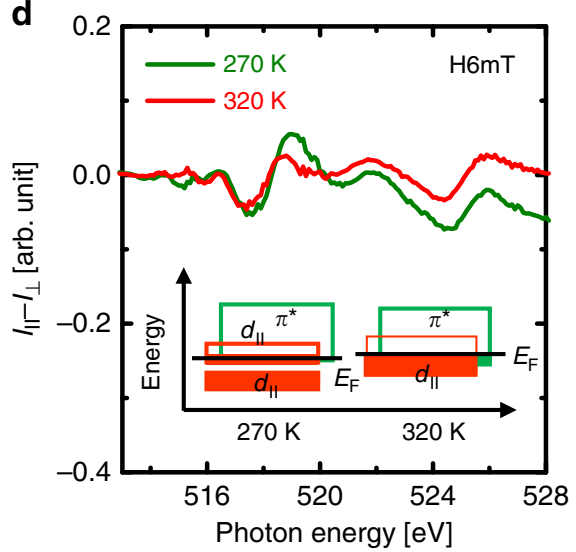

Fig. 4 Oxygen-vacancy-induced isotropic orbital occupancy in $\mathbf{V O}_{\mathbf{2}}$ templates. Polarization-dependent $x$-ray absorption spectroscopy (XAS) at the $V L_{2,3^{-}}$ edges at $270 \mathrm{~K}$ for two heterostructures composed of 2.5-nm-thick $\mathrm{TiO}_{2}$ films grown on $\mathrm{VO}_{2}$ templates under different $p \mathrm{O}_{2}$ (a $\mathrm{H} 24 \mathrm{mT}$, b $\mathrm{H} 6 \mathrm{mT}$ ). Unlike large difference of XAS signal in $\mathrm{H} 24 \mathrm{mT}$ at $270 \mathrm{~K}$ due to the orbital polarization with $\mathrm{V}-\mathrm{V}$ dimerization in the monoclinic $\mathrm{VO}_{2}$, almost no effect on the $\mathrm{XAS}$ signal in $\mathrm{H} 6 \mathrm{mT}$ was observed at $270 \mathrm{~K}$; this result indicates isotropic orbital filling in $\mathrm{H} 6 \mathrm{mT}$ sample even at $270 \mathrm{~K}$. The XLD $\left(I_{\|}-I_{\perp}\right)$ are also shown at both $270 \mathrm{~K}$ and $320 \mathrm{~K}$ for $\mathbf{c ~ H 2 4 m T}$ and $\mathbf{d ~ H 6 m T}$. Oxygen vacancies driven by directional ionic transport in $\mathrm{H} 6 \mathrm{mT}$ tend to increase the crystal symmetry to close to rutile structure by weakening of $\mathrm{V}-\mathrm{V}$ dimerization, so selective filling of $d_{\|}$(inset of $\mathbf{c}$.) changes to isotropic orbital occupancy of $d_{\|}$and $\pi^{\star}$ (inset of $\mathbf{d}$ ) in $\mathrm{VO}_{2}$ templates; the oxygen-vacancy-driven isotropic occupancy leads to metallization at $270 \mathrm{~K}$.

states $^{38}$ showed negligible $\mathrm{Ti}^{3+}$ contribution from the $\mathrm{H} 6 \mathrm{mT}$ was observed compared to $\mathrm{H} 24 \mathrm{mT}$ in $\mathrm{TiO}_{2} / \mathrm{VO}_{2}$ heterostructures, which reveals the suppression of $V_{O}$ formation even at the surface of $\mathrm{TiO}_{2}$ resulting from enhanced oxygen transport across $\mathrm{TiO}_{2} /$ $\mathrm{VO}_{2}$ interface under low $\mathrm{pO}_{2}$; Both XAS and XPS results contradict the typical observation that stoichiometry could be improved in $\mathrm{TiO}_{2}$ under high $\mathrm{pO}_{2}$ by removing $V_{O}{ }^{21,39}$.

\section{Discussion}

This study presents two interesting observations. (1) The increase in directional oxygen transport from $\mathrm{VO}_{2}$ to $\mathrm{TiO}_{2}$ with decrease in $\mathrm{pO}_{2}$ during $\mathrm{TiO}_{2}$ growth, and (2) facile formation of rutile $\mathrm{TiO}_{2}$ epitaxial layer at extremely low temperature $\left(\leq 150^{\circ} \mathrm{C}\right)$. To identify the driving force for spontaneous oxygen loss from $\mathrm{VO}_{2}$ templates, firstly, density functional theory (DFT) calculations were performed to determine values of the lower and upper limit of the chemical potential of oxygen $\left(\mu_{\mathrm{O}}\right)$ for $\mathrm{TiO}_{2}$ and $\mathrm{VO}_{2}$ formation in general:

$\frac{1}{2}\left(E_{\text {tot }}\left[\mathrm{TiO}_{2}\left(\right.\right.\right.$ or $\left.\left.V \mathrm{O}_{2}\right)\right]-\mu_{\mathrm{Ti}}[\mathrm{Ti}($ or $\left.V)]\right) \leq \mu_{\mathrm{O}}\left[\mathrm{TiO}_{2}\left(\mathrm{VO}_{2}\right)\right] \leq \mu_{\mathrm{O}}\left[\mathrm{O}_{2}\right]$.

Our calculations predict that the lower limit of $\mu_{O}$ is $-8.767 \mathrm{eV}$ for $\mathrm{VO}_{2}$ and $-9.624 \mathrm{eV}$ for $\mathrm{TiO}_{2}$ (top of Fig. 5c), which indicates that $\mathrm{TiO}_{2}$ is the only stable compound at $-9.624 \mathrm{eV} \leq \mu_{O} \leq-8.767 \mathrm{eV}$. In the specific $\mu_{O}$ region in which $\mathrm{VO}_{2}$ is thermodynamically unstable, oxygen atoms can preferentially migrate from it to stable $\mathrm{TiO}_{2}$.

Indeed, $\mathrm{VO}_{2}$ and $\mathrm{TiO}_{2}$ coexist at the interfaces in the heterostructures, so the following thermodynamic reactions occur during $\mathrm{TiO}_{2}$ growth:

$$
\mathrm{TiO}_{2-\delta}(s)+\mathrm{VO}_{2}(s) \leftrightarrow \mathrm{TiO}_{2}(s)+\mathrm{VO}_{2-\delta}(s)
$$

Thermodynamic calculations using this reaction yielded a Gibbs free energy $\Delta \mathrm{G}=-18.69 \mathrm{~kJ} / \mathrm{mol}$ at $\delta=0.125$, and $-82.77 \mathrm{~kJ} / \mathrm{mol}$ at $\delta=0.5$ at $T_{\mathrm{G}}=150{ }^{\circ} \mathrm{C}^{40-42}$. Regardless of the degree of oxygen deficiency in grown $\mathrm{TiO}_{2-\delta}$ layer, oxygen ions tend to transfer spontaneously to the $\mathrm{TiO}_{2}$ layer to equilibrate $\mu_{O}$ between the two layers by forming $V_{O}$ in $\mathrm{VO}_{2}$ templates. A thermodynamic driving force between $\mathrm{TiO}_{2-\delta}$ and $\mathrm{VO}_{2}$ still exists even if few monolayer of $\mathrm{TiO}_{2}$ prevents the direct interface between two dissimilar materials, so "remote" oxygen ionic transport from $\mathrm{VO}_{2}$ to $\mathrm{TiO}_{2-\delta}$ is maintained through the few $\mathrm{TiO}_{2}$ monolayer as long as oxygen diffusion is kinetically allowed (Supplementary Figs. 9, 10, 15) ${ }^{16,43}$. To support our observation on the preferred formation of $V_{O}$ in $\mathrm{VO}_{2}$ templates, we also compared the formation energies of $V_{O}$ (and vanadium interstitials $\left(V_{i}\right)$ ) in rutile $\mathrm{VO}_{2}$ and in $\mathrm{TiO}_{2}$ as a function of Fermi level in the band gap of rutile $\mathrm{TiO}_{2}$ (bottom of Fig. $5 \mathrm{c}$ ). Our calculations predict that the formation energy of $V_{O}$ is at 


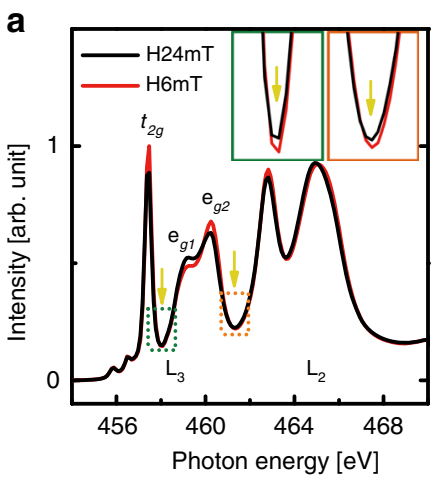

b

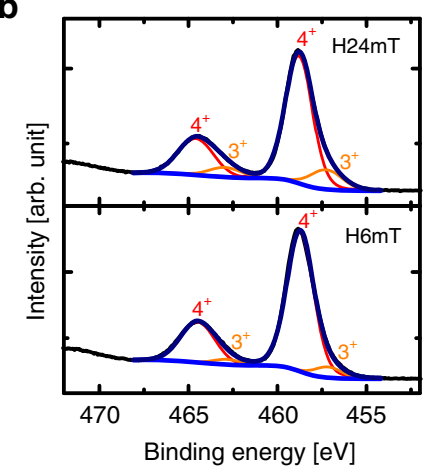

C
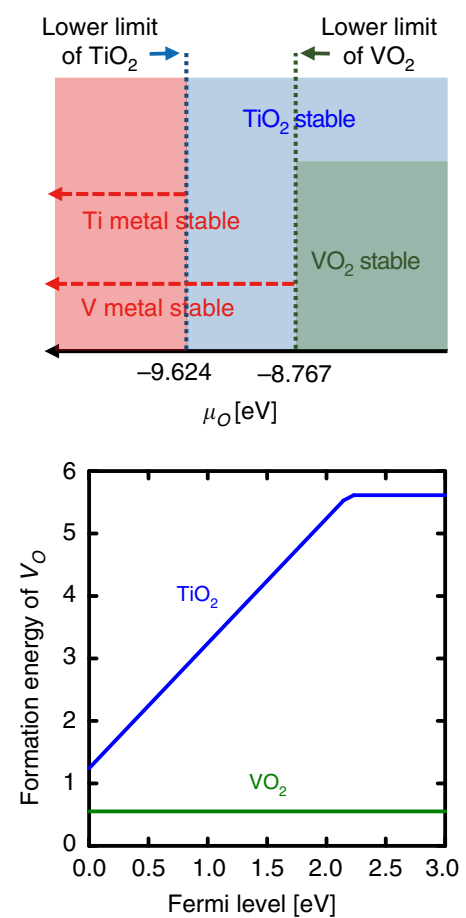

d

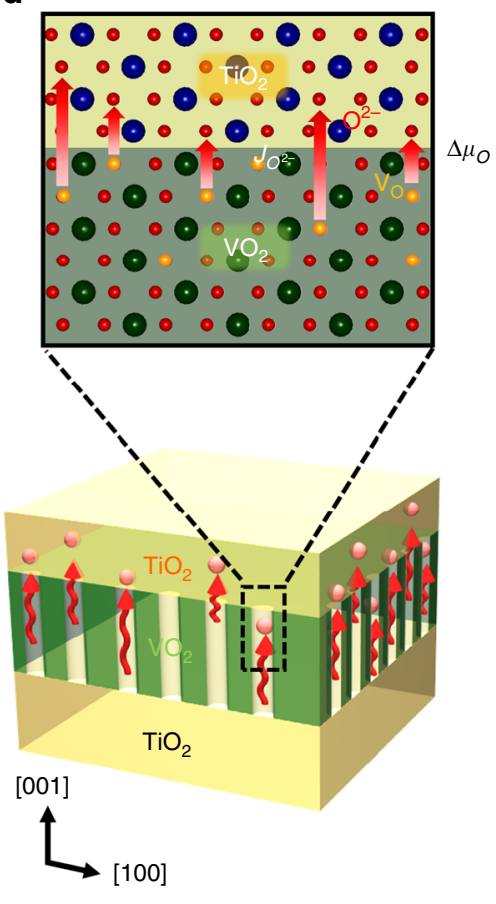

Fig. 5 Facilitated rutile $\mathrm{TiO}_{\mathbf{2}}$ epitaxy by $\boldsymbol{\Delta} \boldsymbol{\mu}_{\mathbf{O}}$ across the $\mathrm{TiO}_{\mathbf{2}} / \mathbf{V O}_{\mathbf{2}}$ interface. a Ti L-edge XAS spectra of $\mathrm{TiO}_{2}$ grown on $\mathrm{VO}_{2}$ templates under different $p \mathrm{O}_{2}$ $(\mathrm{H} 24 \mathrm{mT}, \mathrm{H} 6 \mathrm{mT})$. The Ti $L_{2,3}$-edge XAS signals from the $\mathrm{H} 6 \mathrm{mT}$ were more intense and sharper than from $\mathrm{H} 24 \mathrm{mT}$. $\mathbf{b}$ XPS spectra of the Ti $2 p$ core level of $\mathrm{H} 24 \mathrm{mT}, \mathrm{H} 6 \mathrm{mT}$. negligible Ti ${ }^{3+}$ contribution from the $\mathrm{H} 6 \mathrm{mT}$ was observed compared to $\mathrm{H} 24 \mathrm{mT}$ in $\mathrm{TiO}_{2} / \mathrm{VO}_{2}$ heterostructures, which reveals the suppression of $V_{O}$ formation even at the surface of $\mathrm{TiO}_{2}$ as a result of increased oxygen transport across $\mathrm{TiO}_{2} / \mathrm{VO}_{2}$ interface under low $p \mathrm{O}_{2}$. Both XAS and XPS results reveal increased perfection of rutile $\mathrm{TiO}_{2}$ films after growth at low $\mathrm{pO}_{2}$. c First-principles density functional theory (DFT) calculations to determine values of the lower and upper limit of the chemical potential of $\mu_{\mathrm{O}}$ for $\mathrm{TiO}_{2}$ and $\mathrm{VO}_{2}$ formation. $\mathrm{TiO}_{2}$ is the only stable compound at $-9.624 \mathrm{eV} \leq \mu_{O} \leq-8.767 \mathrm{eV}$. Comparison of the formation energies of $\mathrm{V}_{\mathrm{O}}$ in rutile $\mathrm{VO}_{2}$ and $\mathrm{TiO}_{2}$ as a function of Fermi level in the band gap of $\mathrm{TiO}_{2}$. $\mathbf{d}$ Increased thermodynamic driving force $\Delta \mu_{\mathrm{O}}$, assisted by high ionic kinetics $k_{1}$, across the interface increased the perfection of registry in the lattice of $\mathrm{TiO}_{2}$ films by increasing "effective" $p \mathrm{O}_{2}$ and lowering the activation barrier for epitaxy with concurrent emergence of a metallic $\mathrm{VO}_{2-\delta}$ sacrificial templates.

least $0.69 \mathrm{eV}$ lower in $\mathrm{VO}_{2}$ than in $\mathrm{TiO}_{2}$ and is $\sim 2.0 \mathrm{eV}$ lower that of $V_{i}$ in $\mathrm{VO}_{2}$ (Supplementary Fig. 8).

It should be emphasized that the driving force for ionic flux accelerates with increase in the oxygen deficiency on the formed $\mathrm{TiO}_{2-\delta}$ layers (i.e., decrease in $\mathrm{pO}_{2}$ at which the film was grown) by maximizing chemical potential mismatch $\left(J_{O^{2-}} \propto \Delta \mathrm{G}(\text { or } \Delta \mu)\right)^{10}$. Due to this strengthened driving force for directional oxygen diffusion from $\mathrm{VO}_{2}$ to $\mathrm{TiO}_{2}$, more oxygen vacancies prefer to form in $\mathrm{VO}_{2}$ templates during $\mathrm{TiO}_{2}$ growth as $p \mathrm{O}_{2}$ was decreased. $\Delta \mu_{O}$ across $\mathrm{TiO}_{2} / \mathrm{VO}_{2}$ interfaces in the heterostructure drives oxygen flux $\left(\mathrm{J}_{\mathrm{O}^{2-}}\right)$ as a directional supply of oxygen ionic radical across the interface from $\mathrm{VO}_{2}$ sacrificial layers without the dissociation of oxygen gas molecules ${ }^{10}$. The transferred oxygen ions can "effectively" increase the oxygen partial pressure $\left(\mathrm{pO}_{2}\right)$ and $\mu_{\mathrm{O}}$ at the $\mathrm{TiO}_{2}$ side; paradoxically, low $p \mathrm{O}_{2}$ at the ambient is likely to increase "effective" $p \mathrm{O}_{2}$ (= "external" $p \mathrm{O}_{2}$ from $\mathrm{O}_{2}$ gas + "internal" $\mathrm{pO}_{2}$ across the solid-solid interface) during $\mathrm{TiO}_{2}$ growth on $\mathrm{VO}_{2}$ templates. As a result, the increased "effective" $\mathrm{pO}_{2}$ by the enhanced $\mathrm{O}_{\mathrm{O}^{2-}}$ across the interface magnifies driving force for the formation of rutile $\mathrm{TiO}_{2}$ with stoichiometry in heterostructure (Supplementary Fig. 16); lack of oxidation in the deposited $\mathrm{TiO}_{2-\delta}$ species during the growth is compensated by transferred oxygen ions from the $\mathrm{VO}_{2}$ templates below ${ }^{10,44}$.

For heterogenous nucleation on the substrate during the film growth, the activation energy $\left(\Delta G^{*}\right)$ for the formation of crystalline nuclei could be significantly lowered by increasing the supply of oxygen ions (i.e., increasing the driving force for formation of rutile $\mathrm{TiO}_{2}$ ) based on the following expression ${ }^{45}$.

$$
\Delta \mathrm{G}^{*}=\frac{16 \pi \gamma_{f v}^{3}}{3\left(\Delta \mathrm{G}_{v}-\Delta \mathrm{G}_{S}\right)^{2}} S(\theta)
$$

where $\Delta \mathrm{G}_{v}, \gamma_{f v}, \Delta \mathrm{G}_{S}$, and $S(\theta)$ are the chemical free energy change for the formation of solid rutile $\mathrm{TiO}_{2}$ nuclei, surface free energies, interfacial strain energy and a geometrical factor for heterogeneous nucleation, respectively. At very low $T_{\mathrm{G}} \sim 150^{\circ} \mathrm{C}$, the adatoms freeze in metastable form, so the time constant for crystallization $\left(\tau_{\text {cryst }}\right.$, i.e., $\left.\frac{1}{\tau_{c \text { cryt }}}=\mathrm{A} \cdot \exp \left(-\frac{\Delta G^{*}}{k_{B} T_{g}}\right)\right)$ becomes extremely long due to the high $\Delta \mathrm{G}^{*}$ and insufficient thermal energy; the amorphized or metastable $\mathrm{TiO}_{2}$ films (with nonequilibrium structure) are likely to form due to the kinetic hindrance of crystal formation (e.g., insufficient movement of ablated $\mathrm{TiO}_{2}$ adatoms and/or limited reaction with $\mathrm{O}_{2}$ gas) as observed in our $\mathrm{TiO}_{2} / \mathrm{TiO}_{2}$ homostructure.

In our case, $\mathrm{VO}_{2}$ sacrificial layers from the bottom acts as epitaxial templates for rutile $\mathrm{TiO}_{2}$. They also sacrifice themselves by forming $V_{O}$ in $\mathrm{VO}_{2}$ and thereby supply high concentration of oxygen ions to $\mathrm{TiO}_{2-\delta}$ by magnifying the driving force for the oxygen transport at the $\mathrm{VO}_{2} / \mathrm{TiO}_{2}$ interfaces. Since $\gamma_{f v}$ and $\Delta \mathrm{G}_{S}$ are unlikely to be changed regardless of the existence of $\mathrm{VO}_{2}$ templates (Supplementary Fig. 6 and Fig. 15), greater $\Delta \mathrm{G}_{v}$ induced by $J_{\mathrm{O}^{2}}$ - significantly reduce $\Delta \mathrm{G}^{*}$ in heterostructure than in homostructure. As a result, the large reduction of $\tau_{\text {cryst }}$ by the decrease in $\Delta \mathrm{G}^{*}$ enables unprecedented epitaxy of hightemperature-stabilized $\mathrm{TiO}_{2}$ rutile phase ${ }^{19,23}$ at extremely low 
$T_{\mathrm{G}} \sim 150^{\circ} \mathrm{C}$ by changing the initial stoichiometry of two oxides with different $\mu$ across the interface.

In addition to thermodynamic viewpoint, the transport of charged oxygen ions is kinetically facilitated along the crystallographic [001] direction, which has open channels in anisotropic rutile $\mathrm{VO}_{2}$ and $\mathrm{TiO}_{2}{ }^{15,16}$. One-dimensional empty channels are aligned along the $c$ axis in our $\mathrm{TiO}_{2} / \mathrm{VO}_{2}$ heterostructures and provide the advantage of removing significant amounts of oxygen ions due to a high oxygen diffusion coefficient. Thus, the growth direction of [001] $\mathrm{TiO}_{2}$ films should strongly accelerate the outdiffusion kinetics of oxygen transport (increased $k$ in Fig. 1a) from the $\mathrm{VO}_{2}$ sacrificial templates as a result of mismatch in chemical potential $\left(\Delta \mu_{O}\right.$ in Fig. 1a); significant reduction in oxygen transport across the oxide interface along the [001] direction kinetically facilitates the decrease in $\Delta \mathrm{G}^{*}$ for nucleation of rutile $\mathrm{TiO}_{2}$ phase even at low $T_{\mathrm{G}}$ to support epitaxial growth of rutile $\mathrm{TiO}_{2}$ films on $\mathrm{VO}_{2}$ templates.

On the other hand, the kinetics of oxygen transport will eventually limit our epitaxial growth based on "internal" oxygen transport across the $\mathrm{TiO}_{2} / \mathrm{VO}_{2}$ interface (Supplementary Figs. 11, 12, 13). Since the oxygens should be supplied from the $\mathrm{TiO}_{2} / \mathrm{VO}_{2}$ interfaces through the intervening $\mathrm{TiO}_{2}$ layers, the thickness of "epitaxial" $\mathrm{TiO}_{2}$ will be limited by oxygen diffusion through the intervening $\mathrm{TiO}_{2}$ layer. In fact, while the "epitaxial" thickness linearly increased with growth time in the $\mathrm{TiO}_{2}$ films grown at $300{ }^{\circ} \mathrm{C}$, the "epitaxial" thickness appears to be saturated to be $\sim 10 \mathrm{~nm}$ as a "critical" thickness at $t_{\text {fim }}>10 \mathrm{~nm}$ at $T_{\mathrm{G}} \sim 150^{\circ} \mathrm{C}$ due to scarce source of "internal" oxygen transport $\left(J_{O^{2-}}\right)$ even if the growth time increases (Supplementary Fig. 11). Therefore, the existence of "critical" thickness provides the convincing evidence of our unprecedented low-temperature epitaxy driven by direction oxygen ionic transport.

In summary, unconventional low-temperature epitaxy of rutile $\mathrm{TiO}_{2}$ films was achieved by exploiting the directional transport of oxygen ions across $\mathrm{TiO}_{2} / \mathrm{VO}_{2}$ heterointerfaces. The thermodynamic driving force, assisted by facile ionic pathway along oxygen channel, across the interface enabled more perfect registry in the lattice of $\mathrm{TiO}_{2}$ films by lowering the activation barrier for stable nuclei, with concurrent emergence of a metallic $\mathrm{TiO}_{2} / \mathrm{VO}_{2}$ heterostructures. Contrary to typical experimental condition to obtain $\mathrm{TiO}_{2}$ with better stoichiometry, interestingly, $V_{O}$ formation was diminished under low external $p \mathrm{O}_{2}$, because the accelerated chemical potential mismatch $\left(\Delta \mu_{O}\right)$ under low external $\mathrm{pO}_{2}$ significantly increased "effective" $\mathrm{pO}_{2}$ by the internal oxygen transport across the $\mathrm{TiO}_{2} / \mathrm{VO}_{2}$ interface. Therefore, the controlled ionic transport by $\Delta \mu_{O}$ may offer an opportunity to design a new heterostructure with different degree of freedom at the interfaces as a result of tuning of ionic defects, and also to stabilize thermal-energy-requiring phases simply by interfacing with dissimilar materials with different thermodynamic and kinetic driving force of ionic defects.

\footnotetext{
Methods

Synthesis of epitaxial $\mathrm{TiO}_{2} / \mathrm{VO}_{2}$ heterostructures on $\mathrm{TiO}_{2}$ substrates. Epitaxial $\mathrm{VO}_{2}$ thin films (10-14 nm thick) were grown on (001) $\mathrm{TiO}_{2}$ single-crystal substrates, followed by the growth $\mathrm{TiO}_{2}$ films $(2.5-60 \mathrm{~nm}$ thick) by pulsed laser deposition (PLD). The stoichiometric targets for the synthesis of heterostructures were prepared by sintering stoichiometric powders of $\mathrm{V}_{2} \mathrm{O}_{5}(99.99 \%$, Sigma Aldrich) at $600{ }^{\circ} \mathrm{C}$ for $6 \mathrm{~h}$ and $\mathrm{TiO}_{2}\left(99.95 \%\right.$, Sigma Aldrich) at $1100{ }^{\circ} \mathrm{C}$ for $4 \mathrm{~h}$. First, (001) $\mathrm{TiO}_{2}$ single crystal substrates (Shinkosha CO., LTD) were loaded into the PLD chamber, which was then evacuated to a base pressure of $\sim 1 \times 10^{-6}$ Torr. Then, the rotating $\mathrm{V}_{2} \mathrm{O}_{5}$ targets were ablated by focusing $\mathrm{KrF}$ excimer laser (Coherent Compex Pro $102 \mathrm{~F}, \lambda=248 \mathrm{~nm}$ ) with a fluence of $1 \mathrm{~J} / \mathrm{cm}^{2}$ and repetition rate of $1 \mathrm{~Hz}$. The $\mathrm{VO}_{2}$ growth was performed at fixed $\mathrm{pO}_{2}=12 \mathrm{mTorr}$ and $300^{\circ} \mathrm{C}$, which was selected to induce a steep metal-insulator transition near room temperature from coherently tensile-strained $\mathrm{VO}_{2}$ films. After $\mathrm{VO}_{2}$ growth, the substrate temperature was quenched to $50 \sim 150^{\circ} \mathrm{C}$. Subsequently, $\mathrm{TiO}_{2}$ films were grown on $\mathrm{VO}_{2}$ templates under $6 \mathrm{mTorr} \leq \mathrm{pO}_{2} \leq 24$ mTorr to control the
}

thermodynamic driving force for oxygen ionic transport across the interface at low temperature $\left(T_{\mathrm{G}}=50-150{ }^{\circ} \mathrm{C}\right)$. After the growth of heterostructures, the samples were cooled down to room temperature with rate of $20^{\circ} \mathrm{C} / \mathrm{min}$.

Structural and electrical characterization of heterostructures. To characterize crystal-structure modulation in $\mathrm{TiO}_{2} / \mathrm{VO}_{2} / \mathrm{TiO}_{2}$ heterostructures with different degrees of chemical potential mismatch using $\mathrm{pO}_{2}$ during $\mathrm{TiO}_{2}$ growth, highresolution $\mathrm{X}$-ray scattering measurements were performed using synchrotron radiation at $3 \mathrm{~A}$ MP-XRS $(\lambda \sim 0.11145 \mathrm{~nm}$, energy $\sim 11,125 \mathrm{keV}$ at $\mathrm{Si}(111))$ and at 3D XRD $(\lambda \sim 0.12398 \mathrm{~nm}$, energy $\sim 10 \mathrm{keV}$ at Si (111) beamline of Pohang Light Source-II (PLS-II, Pohang, Republic of Korea), and using an in-house HRXRD (Bruker Discover $8 \mathrm{X}$-ray diffractometer) with $\mathrm{Cu} \mathrm{K}_{\alpha 1}$ radiation $(\lambda=0.15406 \mathrm{~nm})$. The detailed information on in-plane and out-of-plane lattice parameters and strain states of each film in the heterostructures were obtained by using both symmetric $2 \theta-\omega$ scan and asymmetric reciprocal space mapping (RSM) around the (112) reflection. The simulation of symmetric $2 \theta-\omega$ scans was performed using LEPTOS software program. The surface morphology of the films was observed using an atomic force microscope (AFM, VEECO Dimension 3100).

For atomic resolution analysis of crystal structure, the samples were prepared using a dual-beam focused ion beam (FIB) system (Helios G3, FEI). HRTEM and STEM analyses (JEM-ARM200F, JEOL) were performed at $200 \mathrm{kV}$ equipped with a $5^{\text {th }}$ order aberration corrector (ASCOR, CEOS $\mathrm{GmbH}$ ) for forming $0.7 \AA$ probe. The collection semi-angles were 68 to $280 \mathrm{mrad}$ for HAADF, 27 to $110 \mathrm{mrad}$ for LAADF and 10 to $20 \mathrm{mrad}$ for ABF. The obtained raw images were band-pass filtered to reduce background noise (HREM Research Inc.).

The sheet resistance $R_{\mathrm{S}}$ was measured as a function of temperature during the heating and cooling from $250 \mathrm{~K}$ to $340 \mathrm{~K}$ using Hall measurement system. Measurements were carried out in van der Pauw geometry with square samples $(5 \mathrm{~mm} \times 5 \mathrm{~mm})$ and indium Ohmic contacts $(<1 \mathrm{~mm} \times 1 \mathrm{~mm})$ in the sample corners. The four-terminal resistances were measured using a $10-\mu \mathrm{A}$ current.

To investigate electronic structure of $\mathrm{TiO}_{2} / \mathrm{VO}_{2}$ heterostructures, X-ray absorption spectroscopy (XAS) and linear dichroism (XLD) were performed using high sensitivity at the 2A MS beamline at PLS-II. The total electron yield mode with an energy resolution of $\sim 0.1 \mathrm{eV}$ was used for both measurements at a base pressure of $5 \times 10^{-10}$ Torr in the analysis chamber by measuring the sample current $\left(I_{1}\right)$ divided by the beam current $\left(I_{o}\right)$ to remove the variation of beam intensity. The linear dichroism of $\mathrm{V} L_{2,3}$-edge was carried out by using horizontally-polarized or vertically-polarized X-ray beams with photon incidence angle of $22.5^{\circ}$ at the measurement temperatures below $(270 \mathrm{~K})$ and above the $T_{M I}$ $(320 \mathrm{~K})$ of as-grown $\mathrm{VO}_{2}$ films. And then, the Ti $L_{2,3}$-edges XAS measurements were performed on $\mathrm{TiO}_{2} / \mathrm{VO}_{2} / \mathrm{TiO}_{2}$ heterostructures; photon incidence angle was $45^{\circ}$, and measurement temperatures were $270 \mathrm{~K}$ and $320 \mathrm{~K}$. Due to its elementresolved characterization with several nanometer probing depth, Ti $L_{2,3}$-edges spectra were obtained only from the $\mathrm{TiO}_{2}$ epitaxial films on top.

To evaluate the surface stoichiometry of the $\mathrm{TiO}_{2}$ rutile films as a result of directional oxygen transport from $\mathrm{VO}_{2}$ films in our $\mathrm{TiO}_{2} / \mathrm{VO}_{2} / \mathrm{TiO}_{2}$, XPS spectra of Ti $2 p$ core level were acquired on the 4A2 SARPES and 4D PES beam line (PLSII) in an ultra-high vacuum chamber $\left(2 \times 10^{-10}\right.$ Torr $)$. Before measurement, we carefully removed possible contaminants by using gentle Ar surface treatment. Ion sputtering was performed for $4 \mathrm{~min}$ and $20 \mathrm{~min}$ in the preparation chamber under the Ar pressure of $8 \times 10^{-6}$ Torr at anode voltage of $500 \mathrm{~V}$ and $2.5 \mathrm{kV}$. For collect Ti $3 \mathrm{~d}$ spectra, we measured from $475 \mathrm{eV}$ to $445 \mathrm{eV}$ with $50-\mathrm{meV}$ steps at $300 \mathrm{~K}$. The measured spectra were deconvoluted using XPSPEAK41 software.

First-principles calculation. First-principles density functional theory (DFT) calculations were performed using the Projector Augmented Wave (PAW) method and the generalized gradient approximation of Perdew, Burke, and Ernzerhof (PBE) for the exchange-correlation potential as implemented in Vienna Ab-initio Simulation Package (VASP) code ${ }^{46}$. Periodic boundary condition and MonkhorstPack k-point sampling with a $\Gamma$-centered k-point grid of up to $8 \times 8 \times 8$ was used for the Brillouin zone integration. An energy cutoff of $450 \mathrm{eV}$ was used for the plane-wave representation of the wavefunctions and the 3 s electrons of $\mathrm{V}$ and $\mathrm{Ti}$ ions were considered as valence electrons. A Hubbard $U$ correction term was applied to the $\mathrm{V}(U=3.25 \mathrm{eV})$ and $\mathrm{Ti}(U=3.00 \mathrm{eV})$ to properly reproduce the strong on-site Columbic repulsion of $3 \mathrm{~d}$-electrons ${ }^{47}$. Atomic structures were relaxed until all Hellman-Feynman forces were below $0.01 \mathrm{eV} / \AA$. The optimized lattice parameters are $a=4.67 \AA$ and $c=2.52 \AA$ for Ti metal and $a=3.31 \AA$ for $\mathrm{V}$ metal. The optimized lattice parameters are $a=4.559 \AA$ and $c=2.889 \AA$ for rutile $\mathrm{VO}_{2}$, and $a=4.608 \AA$ and $c=2.989 \AA$ for rutile $\mathrm{TiO}_{2}$.

\section{Data availability}

The authors declare that the all the data supporting the finding of this study are available within this article and its Supplementary Information files, and are available from the corresponding author on reasonable request.

Received: 26 July 2019; Accepted: 19 February 2020; Published online: 16 March 2020 


\section{References}

1. Kroemer, H. Nobel lecture: quasielectric fields and band offsets: teaching electrons new tricks. Rev. Mod. Phys. 73, 783-793 (2001).

2. Dingle, R., Stormer, H. L., Gossard, A. C. \& Wiegmann, W. Electron mobilities in modulation-doped semiconductor heterojunction superlattices. Appl. Phys. Lett. 33, 665 (1978).

3. Ohtomo, A. \& Hwang, H. Y. A high-mobility electron gas at the $\mathrm{LaAlO}_{3} /$ $\mathrm{SrTiO}_{3}$ heterointerface. Nature 427, 423 (2004).

4. Lee, D. et al. Isostructural metal-insulator transition in $\mathrm{VO}_{2}$. Science $\mathbf{3 6 2}$ 1037-1040 (2018).

5. Li, Y. Y. \& Chueh, W. C. Electrochemical and chemical insertion for energy transformation and switching. Annu. Rev. Mater. Res. 48, 137-165 (2018).

6. Tsui, D. C., Stormer, H. L. \& Gossard, A. C. Two-dimensional magnetotransport in the extreme quantum limit. Phys. Rev. Lett. 48, 1559 (1982).

7. Morkoc, H. \& Solomon, P. M. The HEMT: a superfast transistor. IEEE Spectr. 21, 28-35 (1984)

8. Fuller, E. J. et al. Li-ion synaptic transistor for low power analog computing. Adv. Mater. 29, 1604310 (2017).

9. Jeong, J. et al. Suppression of metal-insulator transition in $\mathrm{VO}_{2}$ by electric field-induced oxygen vacancy formation. Science 339, 1402-1405 (2013).

10. Guo, E. J. et al. Oxygen diode formed in nickelate heterostructures by chemical potential mismatch. Adv. Mater. 30, 1705904 (2018)

11. Veal, B. W. et al. Interfacial control of oxygen vacancy doping and electrical conduction in thin film oxide heterostructures. Nat. Commun. 7, 11892 (2016).

12. Scheiderer, P. et al. Tailoring materials for mottronics: excess oxygen doping of a prototypical mott insulator. Adv. Mater. 30, 1706708 (2018)

13. Lee, S. W., Liu, Y. Q., Heo, J. \& Gordon, R. G. Creation and control of twodimensional electron gas using Al-based amorphous oxides $/ \mathrm{SrTiO}_{3}$ heterostructures grown by atomic layer deposition. Nano Lett. 12, 4775-4783 (2012).

14. Leighton, C. Electrolyte-based ionic control of functional oxides. Nat. Mater. 18, 13-18 (2019)

15. Jeong, J. et al. Giant reversible, facet-dependent, structural changes in a correlated-electron insulator induced by ionic liquid gating. Proc. Natl. Acad. Sci. USA 112, 1013-1018 (2015).

16. Passarello, D., Altendorf, S. G., Jeong, J., Samant, M. G. \& Parkin, S. S. P. Metallization of epitaxial $\mathrm{VO}_{2}$ films by ionic liquid gating through initially insulating $\mathrm{TiO}_{2}$ layers. Nano Lett. 16, 5475-5481 (2016).

17. Yoon, $\mathrm{H}$. et al. Reversible phase modulation and hydrogen storage in multivalent $\mathrm{VO}_{2}$ epitaxial thin films. Nat. Mater. 15, 1113-1119 (2016).

18. Yoon, H., Park, J., Choi, S.-Y., Lee, D. \& Son, J. Facet-dependent phase control by band filling and anisotropic electron-lattice coupling in $\mathrm{HVO}_{2}$ epitaxial films. Adv. Electron. Mater. 4, 1800128 (2018).

19. Mitsuhashi, T. \& Kleppa, O. J. Transformation enthalpies of the $\mathrm{TiO}_{2}$ polymorphs. J. Am. Ceram. Soc. 62, 356-357 (1978).

20. Ranade, M. R. et al. Energetics of nanocrystalline $\mathrm{TiO}_{2}$. Proc. Natl. Acad. Sci. USA 99, 6476-6481 (2002).

21. Bayati, M. R., Joshi, S., Narayan, R. J. \& Narayan, J. Low-temperature processing and control of structure and properties of $\mathrm{TiO}_{2} / \mathrm{c}$-sapphire epitaxial heterostructures. J. Mater. Res. 28, 1669-1679 (2013).

22. Chen, S. et al. Ultrahigh-vacuum metalorganic chemical-vapor-deposition growth and in-situ characterization of epitaxial $\mathrm{TiO}_{2}$ films. J. Vac. Sci. Technol. A 11, 2419-2429 (1993).

23. Hanaor, D. A. H. \& Sorrell, C. C. Review of the anatase to rutile phase transformation. J. Mater. Sci. 46, 855-874 (2010).

24. Muller, D. A., Nakagawa, N., Ohtomo, A., Grazul, J. L. \& Hwang, H. Y. Atomic-scale imaging of nanoengineered oxygen vacancy profiles in $\mathrm{SrTiO}_{3}$. Nature 430, 657-661 (2004).

25. Zhou, H., Chisholm, M. F., Gupta, A., Pennycook, S. J. \& Narayan, J. Twodimensional metamaterials for epitaxial heterostructures. Curr. Opin. Solid State Mater. Sci. 18, 46-52 (2014).

26. Fan, L. L. et al. Strain dynamics of ultrathin $\mathrm{VO}_{2}$ film grown on $\mathrm{TiO}_{2}$ (001) and the associated phase transition modulation. Nano Lett. 14, 4036-4043 (2014).

27. Yang, $\mathrm{M}$. et al. Suppression of structural phase transition in $\mathrm{VO}_{2}$ by epitaxial strain in vicinity of metal-insulator transition. Sci. Rep. 6, 23119 (2016).

28. Zhang, J. et al. Evolution of structural and electrical properties of oxygen deficient $\mathrm{VO}_{2}$ under low temperature heating process. ACS Appl. Mater. Interfaces 9, 27135-27141 (2017)

29. Abbate, M. et al. Soft-x-ray-absorption studies of the electronic-structure changes through the $\mathrm{VO}_{2}$ phase transition. Phys. Rev. B 43, 7263-7266 (1991).

30. Aetukuri, N. B. et al. Control of the metal-insulator transition in vanadium dioxide by modifying orbital occupancy. Nat. Phys. 9, 661-666 (2013).
31. Haverkort, M. W. et al. Orbital-assisted metal-insulator transition in $\mathrm{VO}_{2}$. Phys. Rev. Lett. 95, 196404 (2005).

32. Zhang, Z. et al. Evolution of metallicity in vanadium dioxide by creation of oxygen vacancies. Phys. Rev. Appl. 7, 034008 (2017).

33. Karel, J. et al. Distinct electronic structure of the electrolyte gate-induced conducting phase in vanadium dioxide revealed by high-energy photoelectron spectroscopy. ACS Nano 8, 5784-5789 (2014).

34. Krüger, P. Multichannel multiple scattering calculation of $L_{2,3}$-edge spectra of $\mathrm{TiO}_{2}$ and $\mathrm{SrTiO}_{3}$ : Importance of multiplet coupling and band structure. Phys. Rev. B 81, 125121 (2010).

35. Kucheyev, S. O. et al. Electronic structure of titania aerogels from soft x-ray absorption spectroscopy. Phys. Rev. B 69, 245102 (2004)

36. Chen, C. L. et al. Electronic properties of free-standing $\mathrm{TiO}_{2}$ nanotube arrays fabricated by electrochemical anodization. Phys. Chem. Chem. Phys. 17, 22064-22071 (2015).

37. Chen, C., Avila, J., Frantzeskakis, E., Levy, A. \& Asensio, M. C. Observation of a two-dimensional liquid of Frohlich polarons at the bare $\mathrm{SrTiO}_{3}$ surface. Nat. Commun. 6, 8585 (2015).

38. Biesinger, M. C., Lau, L. W. M., Gerson, A. R. \& Smart, R. S. C. Resolving surface chemical states in XPS analysis of first row transition metals, oxides and hydroxides: Sc, Ti, V, Cu and Zn. Appl. Surf. Sci. 257, 887-898 (2010).

39. Ohtomo, A. \& Hwang, H. Y. Growth mode control of the free carrier density in $\mathrm{SrTiO}_{3-\delta}$ films. J. Appl. Phys. 102, 083704 (2007).

40. Waldner, P. \& Eriksson, G. Thermodynamic modelling of the system titanium-oxygen. Calphad 23, 189-218 (1999).

41. Okinaka, H., Kosuge, K. \& Kachi, S. Phase equilibria and thermodynamic properties in the $\mathrm{V}_{\mathrm{n}} \mathrm{O}_{2 \mathrm{n}-1}$ system. J. Jpn. Inst. Met. 12, 44-48 (1971).

42. Knacke O., Kubaschewski O. \& Hesselmann K. Thermochemical Properties of Inorganic Substances (Springer, 1991)

43. Kim, H., McIntyre, P. C., Chui, C. O., Saraswat, K. C. \& Stemmer, S. Engineering chemically abrupt high-k metal oxide/silicon interfaces using an oxygen-gettering metal overlayer. J. Appl. Phys. 96, 3467-3472 (2004).

44. Zhu, J. X. et al. Probing vacancy behavior across complex oxide heterointerfaces. Sci. Adv. 5, eaau8467 (2019).

45. Ohring M. Materials Science of Thin Films. (Academic Press, 1991).

46. Perdew, J. P., Burke, K. \& Ernzerhof, M. Generalized gradient approximation made simple. Phys. Rev. Lett. 77, 3865-3868 (1996).

47. Hautier, G., Ong, S. P., Jain, A., Moore, C. J. \& Ceder, G. Accuracy of density functional theory in predicting formation energies of ternary oxides from binary oxides and its implication on phase stability. Phys. Rev. B $\mathbf{8 5}$ 155208 (2012).

\section{Acknowledgements}

We acknowledge support for this work by Samsung Research Funding \& Incubation Center of Samsung Electronics under Project Number SRFC-TA1703-09. S.-Y.C., H.S. and G.-Y.K. acknowledge the support of the Global Frontier Hybrid Interface Materials of the National Research Foundation of Korea (NRF) funded by the Ministry of Science and ICT (2013M3A6B1078872).

\section{Author contributions}

J.S., Y.P., M.J. and D.Y. conceived the idea and designed the study; Y.P. and M.J. performed the film growth, X-ray diffraction, transport measurement with the assistance of D.Y. and H.H.; Y.P. and M.J. performed the synchrotron X-ray spectroscopy with the assistance of Y.K.; H.S., G.-Y.K., K.S. and S.-Y.C. characterized the samples by scanning transmission electron microscopy; D.L. performed first-principles calculations; J.S. and Y.P. wrote the manuscript and all authors commented on it; J.S. directed the overall research

\section{Competing interests}

The authors declare no competing interests.

\section{Additional information}

Supplementary information is available for this paper at https://doi.org/10.1038/s41467020-15142-x.

Correspondence and requests for materials should be addressed to J.S.

Peer review information Nature Communications thanks the anonymous reviewers for their contribution to the peer review of this work.

Reprints and permission information is available at http://www.nature.com/reprints

Publisher's note Springer Nature remains neutral with regard to jurisdictional claims in published maps and institutional affiliations. 
(c) (i) Open Access This article is licensed under a Creative Commons Attribution 4.0 International License, which permits use, sharing, adaptation, distribution and reproduction in any medium or format, as long as you give appropriate credit to the original author(s) and the source, provide a link to the Creative Commons license, and indicate if changes were made. The images or other third party material in this article are included in the article's Creative Commons license, unless indicated otherwise in a credit line to the material. If material is not included in the article's Creative Commons license and your intended use is not permitted by statutory regulation or exceeds the permitted use, you will need to obtain permission directly from the copyright holder. To view a copy of this license, visit http://creativecommons.org/ licenses/by/4.0/.

(C) The Author(s) 2020 